\title{
The strategic positioning and configuration of national mapping organisations as enablers of economic and social growth in South Africa
}

\author{
M. Denner and H. Oosthuizen* \\ University of Stellenbosch Business School, \\ University of Stellenbosch, PO Box 610, Bellville 7535, Republic of South Africa \\ ho2@usb.ac.za
}

Received June 2008

\begin{abstract}
This paper explores the transferability and application of business-driven strategic thinking to that of a public sector context, namely national mapping organisations. These organisations exist throughout the world because the economies of the world require geospatial information to support economic and social growth. As such their strategic positioning within government is of prime importance. In South Africa, however, there is a paucity of knowledge in this regard and consequently triggered the research which forms the basis of this paper.
\end{abstract}

A macro-environmental analysis suggests significant growth opportunities for the South African geospatial industry, fuelled by a micro-industry borne out of the 2010 Soccer World Cup event. A profile description of the characteristics of consequence, boundaries between the private and public the industry and expected changes reflect a large industry which is expanding at a rapid rate but is fragmented and displays a complex network-system of inter and intra-industry relationships. As such it is attracting increasing numbers of competitors but, as an industry, appears to be slow to adjust to technological advancement. An internal analysis of the value chain of the National Mapping Organisation (NMO), the single most important player in the local public sector geospatial industry, reveals significant value creation in its inhouse activities. However, the external deconstructed operations, outbound logistics and procurement processes are not allowing the organisation to realise any benefits from efficiencies it may introduce. Key to achieving efficiencies lies in the human capital, which by all accounts, it is failing to retain.

Future strategic thrusts for the NMO have been identified by constructing a SWOT model and by analysing its relative competitive strength. These thrusts were found to concentrate on actions and themes related to staff, communication, marketing, general management, production (cost and capacity) and product (quality and innovation). Interpreting and applying those themes on an interorganisational basis will enable the NMO to best position itself in the industry. In this regard sufficient related strategic fit is evident between the value chains of the NMO, The Satellite Application Centre (SAC) and Statistics South Africa (Stats SA), enabling the NMO to leverage on the sales, marketing and distribution activities of SAC and the financial leveraging capabilities of Stats SA.

This paper has presented an example of how delivering an efficient and effective service delivery may be hampered through the inappropriate strategic configuration of South African public sector activities. It is therefore suggested that the government revisits the strategic positioning of public sector organisations engaged in the provision of geospatial information.

*To whom all correspondence should be addressed.

\section{Introduction}

Leaders and managers of governments, and in fact all public organisations, today face numerous and turbulent external challenges. This was not always the case and until circa the 1980's public organisations internationally focused their strategic thinking mainly on internal resource management and efficiencies. This, however, has changed with the emergence of complex environmental drivers of organisational change in the public sector. As a sectors started to erode and it became apparent to the latter that the best response to environmental instability was to adopt and implement models which followed the patterns suggested for competitive private sector organisations.
In Africa many governments have embarked on comprehensive strategic reforms aimed at improving the quality of life of their citizens, and creating new government machineries to establish efficient and effective strategic management systems. This has been labelled New Public Management (Economic Commission for Africa, 2003:8) and describes a management culture that emphasises the centrality of the citizen or customer, as well as acceptability for results. Unfortunately, however, according to the Economic Commission for Africa (2003:viii): “..... public service management remains at a lethargic stage”.

In South Africa too the government has committed itself to the sound management of the country's resources in such a manner that basic as well as strategic public services are 
delivered (Lenepa, 2006:24). Through the three sphere government system mandates are determined (parliament being the oversight body) which in turn set goals and direction. Policy directives communicate strategy as it is embodied in business models, organisation structures, funding strategy and performance measurement. Basically this system constitutes the classical "private sector or business" model of the formulation (policy input and decisions), implementation (policy statements and execution) and control/evaluation/monitoring (policy review of results and impact) of strategic programmes, projects, processes and procedures.

Against this context it is considered that national mapping organisations in South Africa present an excellent case study to explore and illustrate the possibility and practical applicability of the transferability of business driven strategic thinking to public sector organisations.

\section{Background, research problem and research methodology}

National mapping organisations exist throughout the world because the economies of the world require geographical information to support economic and social growth. Nations require systems and processes designed to deliver highly accurate geospatial information as input to the public activities of inter alia defence, emergency services, policymaking as well as increasing cost and time efficiencies through co-ordination and collaboration between users. The provision of geospatial information is thus considered to be in the national interest and the challenge for any country is therefore to decide on strategic business and sectoral positioning models for the provision of geospatial information that would best suit the type of government and its long term aims.

With regard to the above it has been noted that it can probably be best achieved if these organisations move from a pure government department (public sector) to a more commercial entity (private sector) if they are to survive in a time of economic growth and prosperity (Maguire, 2003:1). Furthermore, in South Africa, it has been mooted that single government departments move into a more dynamic integrated model and system where synergistic services are clustered together to the convenience of the citizen, through a single point of entry (Fraser-Moleketi, 2007:1).

Considering the foregoing background, the research problem addressed in this paper is how to best reposition national mapping organisations within the South African public sector to provide an effective and seamless service delivery. As a basis, this will serve adapted frameworks of the Tenstep Strategy Change Cycle for the public sector (Bryson, 2004:33) and the Five-phase Strategy Process as it applies to the private sector (Thompson, Strickland \& Gamble, 2007:20)

The methodology for collecting the required data to provide the input into the above-mentioned frameworks constituted both primary and secondary research methods. The latter has been obtained by means of an extensive literature search and includes books and articles and inter alia also relevant legislation, in-house documentation and planning documents.

Primary information was generated during 2007 by conducting interviews with senior people who were considered to be knowledgeable about the topic under investigation, i.e. purposive sampling. Seventeen interviews were conducted and covered a spectrum of senior public sector officials employed by national mapping organisations, senior public sector officials responsible for the acquisition of earth imagery for the respective government departments within which they are employed, key public sector role players in developing policies around space imagery and, finally, members in the private mapping industry involved in the supply of earth imagery to the public sector. Separate discussion guides were prepared for respondents internal and external to national mapping organisations.

For the purposes of this paper a research report by Denner (2007) serves as the main source of reference. Where deemed appropriate, acknowledgement will be given to particular pages in the report as well as to other selected references.

\section{Structure of this paper}

The paper firstly describes some common global trends regarding national mapping organisations within their respective government structures. This is, secondly, followed by a brief outline of the structure and environment of government departments in South Africa and the evolving position of the National Mapping Organisation (NMO). The third and fourth parts constitute the research body of the paper and include respectively a strategic analysis of the geospatial information industry with special reference to South Africa, and an internal strategic analysis of the South African NMO. Part five directly addresses the research problem and explores the repositioning of the NMO within the context of the viability of a generic related corporate strategy for those South African public organisations engaged in the geospatial information industry. The paper is concluded with a summary, conclusions and recommendations.

\section{Common global trends in national mapping organisations}

A number of common trends can be identified which provide insight into the constant need for national mapping organisations to best serve the needs of their respective user communities. These trends also provide a clear indication that mapping organisations throughout the world are constantly having to reassess their strategic positioning to be providers of a service that is not always seen as crucial within the public sector. These trends are considered below.

\section{Common trends in strategic positioning within government}

From a strategic perspective, a common trend identified is the need for these organisations to constantly reassess their strategic position within the government to ensure that they 
remain relevant. This is irrespective of the nature of the government or economy of the country and mainly a result of national mapping activities being viewed as a means to an end, rather than an end in itself. Examples are Australia, India and the United States.

\section{Common trends in support of economic growth}

From an economic perspective, a key driving force is the critical need for access to information that is current and easily accessible to promote economic and social growth and development. This trend is common throughout all the countries discussed. A further trend is the need for common standards and interoperability of systems within the various spheres of government to facilitate a sharing of information and a minimisation of cost and duplication. It is interesting to note that in the Australian context the extent of duplication is virtually non-existent, made possible through the establishment of sound partnerships across government with clearly defined roles and objectives.

\section{Common trends in the mode of operation}

In many of the countries the mode of operation of organisations has been redefined from that of the supply of products to that of service providers, grouping together common activities across governments to provide effective service delivery. In so doing, the strategic issue of providing an effective service delivery across government has been addressed through the grouping together of related disciplines in the supply of geospatial information under the same corporate umbrella to capitalise on resource strengths and common goals.

\section{Availability of resources}

Apart from the three major common trends discussed above, the issue of resources is relatively more apparent in developing countries only, such as India. As the technological impact takes hold in that country, it is faced with a workforce with almost redundant skills. This problem does not appear to be apparent in the developed countries studied, but could relate to other developing countries. Australia has indicated that this problem does not really impact on its national mapping activities, although it is a concern in the broader economy of that country.

\section{Structure and environment of government departments and position of the national mapping organisation}

With the creation of the Union of South Africa on 31 May 1910, provision was made for the creation of executive departments in order to provide essential services. There was, however, a systematic proliferation of public institutions in what seems to be an attempt at solving every societal problem that occurred. This trend continued when the Republic of South Africa was constituted (1961) but it was stemmed in 1979 through a programme of nationalisation. This programme, however, was reversed with the establishment of a three-chamber parliament (1983) and the total number of central government departments almost doubled from 22 in 1979 to 38 in 1987. The abolition of the three-chamber parliament (1993) led to some consolidation and eventual restructuring with the introduction of the White Paper on Transforming the Public Service (1995). This resulted in that certain public sector organisations whose services were seen as merely a means to an end, and not an end in itself, would find difficulty in motivating for extensive government funding. For them it would be necessary to reconsider the way in which they conduct their business. One such organisation was the NMO which was chosen as a case study to examine the possibility of reinventing it into a more entrepreneurial enterprise.

Prior to 1995 the NMO was consolidated with various functions around land issues in the Office of the Chief Directorate: Surveys and Land Information. As such it formed part of the Department of Land Affairs (DLA). Following an internal work study, a separate national mapping component was formed and named the Chief Directorate: Surveys and Mapping. The duty of the Chief Director was to be head of the NMO. This arrangement was not fully successful mainly due to an immense loss of skills (particularly white males) during the 1990's as well as the NMO's positioning within the public sector. This latter issue was considered the prime reason for the NMO not being able to evolve to more customised and innovative products and services which were required by the market needs. Consultants were called in and subsequently advised in 2000 that the NMO be strategically positioned outside of the constraints of the public sector, to better satisfy the client needs. This recommendation was not acceptable to the government and the consultants were requested to look at alternatives. A task team was established in 2001 to assess all alternatives (hence known as the Casino Royale Investigation). Their core recommendation was that the NMO move from being product driven to being client driven and that a vision be clarified to achieve this. This, unfortunately, was too narrow a criterium to serve as a point of departure for sound long-term strategic planning by the NMO. A paucity of any further developments triggered the research which forms the basis of this paper.

\section{A strategic analysis of the geospatial information industry}

For the purposes of this paper the definition of the geospatial information industry includes both aerial photography and satellite imagery, with a focus on those organisations within the public sector. Whilst the emphasis is on South Africa, reference will be made to the global perspective where relevant.

The discussion commences with an overview of macroenvironmental factors and their impact on the industry. This is followed by a strategic description of the industry ecosystem which includes the industry attractiveness (industry profile, driving forces and strategic landscape) and those industry components that determine an organisation's position and future competitive success within that industry (strategic group map and industry key success factors). 


\section{Macro-environmental factors and their impact on the industry}

The Peste-analysis is used as the framework to evaluate the impact of macro-environmental factors, i.e. PoliticalEconomic-Social-Technological-Environmental.

\section{Political}

The last twenty years in the history of South Africa has seen significant changes to the political dispensation. The advent of a new democracy for the country has shifted the focus from that of apartheid segregation to an all inclusive society. In the apartheid years, the focus of the geospatial industry was mainly on the so-called white areas where much of the economic development was focused. With the new democracy, the focus shifted to promoting economic development in previously disadvantaged sectors of the country.

There has also been a significant move across government towards a sharing of information. This may have been prompted by the enactment of the Promotion of Access to Information Act, no 2 of 2000. Furthermore, there has been an acceptance across government of the benefits of a pooling of resources, providing greater negotiating power towards international suppliers of satellite imagery. By implication, access has been provided to those who previously were unable to afford the acquisition costs of such data, prompting an increased familiarity with the benefits of geospatial information in the decision-making environment.

\section{Economic}

The South African government was mandated in 2004 to reduce poverty and unemployment by 50 percent, by the year 2014. The Freedom Charter of 1955 and Ready to Govern of 1992 laid the foundation for building an economy that meets the needs of the South African people in a more equitable manner. This has provided for a foundation of good economic policies, positive domestic sentiment and a favourable international environment. The growth opportunities now exist to consolidate these gains and to perform at even a higher level.

The provision of geospatial data underpins any strategies aimed at making progress in economic growth. Furthermore, the World Cup Soccer tournament is expected to do much to improve the economy and foster growth. By all accounts, a significant upgrade of infrastructure is needed for the hosting cities to cope with the influx of tourists during that period. This has done much to create a micro economy, supported by geospatial information for the development of effective policing, provision of adequate transport and planning of stadiums, amongst others.

The impact that the above has for the geospatial industry, both public and private, is immense. In this context, public sector organisations need to respond effectively to avoid a failed attempt at hosting a world cup event. This furthermore has very positive implications for the growth of the private sector geospatial industry whose role would be to undertake the contracts to produce the data for public sector consumption. If these organisations plan effectively, and utilise this window of opportunity as a means of transferring skills in the handling of geospatial information to the public sector clients, an opportunity exists to create further maintenance contracts of the currency of information in the geospatial databases that reside in the public sector. This would alleviate concerns raised around the sustainability of the micro industries following the World Cup Soccer event.

\section{Social}

South Africa's black middle class has grown significantly over the last number of years, with the associated significant increase in spending power. This presents major new opportunities to the geospatial industry, particularly in the provision of location based technologies and the associated information content. This in turn creates new markets for service providers in the geospatial industry. Furthermore, the increased access to Internet technologies available presents new opportunities for growth, particularly amongst those income groups with significant amounts of disposable income.

\section{Technology}

The increased awareness and interest in location based technologies present significant opportunities for growth for the providers of geospatial information to support these technologies. Here, content that is current and accurate will ensure a significant gain in market share for those service providers. Increased access to Internet technologies presents opportunities for online marketing of products and services. However, it must be noted that bandwidth in South Africa remains problematic as the imagery provided by the geospatial industry often requires significant bandwidth capacity for effective distribution.

\section{Environmental}

The impact of various environmental factors, such as the changing weather patterns, which cause flooding in some areas and droughts in others, requires that, to implement effective disaster management strategies, information must be current and easily accessible. For instance, floods in the southern Cape during 2007 resulted in a dire need for geospatial information that was current and easily accessible to allow for an accurate assessment of the flood damage and the development of disaster relief strategies.

\section{Summary}

The Peste-analysis describes the macro-environmental factors and their impact on the geospatial industry. A key theme is the political intent to sustain economic growth which presents significant opportunities for the geospatial industry. It is furthermore fuelled by a micro-industry borne out of the 2010 Soccer World Cup event and the impact that this has on economic development.

\section{Strategic description of the industry ecosystem}

A strategic description of the industry ecosystem includes the determination of the industry attractiveness as well as an 
investigation into those components which determine an organisation's current position and future competitive success within that industry.

\section{Industry attractiveness}

Determining the attractiveness of an industry includes a profile description of its current characteristics, forces driving industry change and competitive forces which shape the strategic landscape.

\section{Industry profile: Current characteristics}

Thompson, et al. (2007:53) defines an industry's characteristics as such factors as overall size and market growth rate, the geographic boundaries of the market, the number and size of competitors, the factors that affect a buyer's choice between products, the pace of technological change and product innovations, economies of scale, learning curve effects and technological. These factors determine the current industry profile and are summarised for the geospatial information industry in Table 1 below.

The status quo of the characteristics of the geospatial information industry can be summerised in an overall profile as follows. It is a large industry and is growing fast, particularly the digital imagery segment. Growth is inter alia accellerated by extending boundaries, technological change and product innovations. Economies of scale is of importance and competition is increased by the entry of smaller players. A need exists for skills-training in the industry.

Whilst the above provides a profile of the current situation, an industry environment is not static but is in a continuous state of fluctuation. These fluctuations and changes are caused by driving forces and are addressed in the next section.

\section{Table 1: Profile of geospatial information industry}

\begin{tabular}{|c|c|}
\hline Industry characteristic & Status quo \\
\hline Overall size and growth rate & $\begin{array}{l}\text { Globally the industry generated values of } \$ 5.39 \text { billion in } 2002 \text {, with expectation for } \\
2007 \text { being } \$ 8.33 \text { billion. Annual growth rate is estimated between } 10-30 \text { percent. } \\
\text { In South Africa the industry generated } \$ 3 \text { million in } 2002 \text {. The growth trend is expected } \\
\text { to be in close correlation with the global trend. }\end{array}$ \\
\hline Geographic boundaries of the market & $\begin{array}{l}\text { The digital age has placed information at the core of economic activity and has given rise } \\
\text { to the opening up of new markets particularly in the transport, energy and construction } \\
\text { sectors. Geographic boundaries which used to be restricted to South Africa, now extend } \\
\text { deep into the African continent. }\end{array}$ \\
\hline Number and size of competitors & $\begin{array}{l}\text { In the past the industry was characterised by a few dominant players. Now, however, the } \\
\text { increasing demand for geospatial information, coupled with the relatively low cost of } \\
\text { entry is making the industry very attractive for an increasing number of smaller players. }\end{array}$ \\
\hline Buyer’s choice & $\begin{array}{l}\text { A buyer's choice is essentially focused on selecting between aerial photography and } \\
\text { satellite imagery. The latter is becoming increasingly available with fast turnaround } \\
\text { times. The buyer preference for this segment is further boosted by a perception of an } \\
\text { intrigue for satellite imagery. }\end{array}$ \\
\hline Pace of technological change & $\begin{array}{l}\text { The industry has experienced significant technological change in recent years. For } \\
\text { example, the introduction of the digital aerial survey camera, the availability of detailed } \\
\text { digital elevation models (DEM) from anywhere in the world and advances in the } \\
\text { capturing of field data, away from paper-based systems. }\end{array}$ \\
\hline Product innovations & $\begin{array}{l}\text { Product innovations such as Google Earth have positive effects on the growth of the } \\
\text { industry as it creates an awareness of the depth of information that can be derived from a } \\
\text { digital Geographic Information System (GIS) environment. }\end{array}$ \\
\hline Economics of scale & $\begin{array}{l}\text { The pooling of funding by government departments for the provision of imagery by the } \\
\text { public sector industry provides the potential for significant cost advantages. }\end{array}$ \\
\hline Learning curve effects & $\begin{array}{l}\text { The lack of knowledge to implement sophisticated equipment and the consequent need } \\
\text { for add-on products such as training, are causing significant learning curve costs to the } \\
\text { public sector industry. This provides significant opportunities for the private mapping } \\
\text { industry to assist with skills development. }\end{array}$ \\
\hline Technological & $\begin{array}{l}\text { The public sector industry is characterised by two extreme scenarios in terms of } \\
\text { technological advancement, and the implementation thereof. On the one hand, many } \\
\text { organisations are still using the old hardcopy paper map system, whilst, for example, the } \\
\text { Satellite Application Centre (SAC) and the NMO have kept abreast of developments. }\end{array}$ \\
\hline
\end{tabular}




\section{Forces driving industry change}

Industry change is typically reflected in changes in the size and nature of the industry. From the previous paragraph it is evident that the geospatial information industry is clearly in the rapid growth phase of its life cycle. The nature of the industry is driven by changes emanating from advancing technologies in the capturing and processing of aerial imagery. Whilst these technologies are very expensive, industry players will have to adapt if they wish to remain competitive.

\section{Strategic landscape}

The strategic landscape of an industry is best expressed by the application of the so-called Porter's Five Forces model (Porter, 1980:4) which draws on the findings of the analyses of the current industry profile and driving forces for its construction. As such it represents a measurement of the overall attractiveness of an industry. The following paragraphs provide an adaption of the five forces analysis as it applies to the South African public sector geospatial information industry.

Rivalry. Rivalry amongst organisations in the public sector geospatial information industry is mainly between the NMO and the SAC but the intensity thereof is moderated by the fact that they serve mainly different market segments. However, the SAC has, in recent years, managed to negotiate inter-governmental licences whereby access is provided to lower resolution satellite imagery at zero cost for government departments. A trend has thus been established to pool financial resources amongst government departments. Rivalry could probably be described as weak to moderate.

New entrants. In the context of this analysis new entrants relate to the potential of entry of private sector competitors that will be assessed as suppliers of products to government departments. This potential is increasing in the light of the inability of government departments to regulate suppliers in terms of professional registration. Thus, increasingly organisations with the slightest experience and relatively small capital outlay are entering the industry. Furthermore, broad-based black economic empowerment (BEE) initiatives are creating opportunities for organisations to transform themselves into a BEE environment with better opportunities to secure government contracts. This force must be regarded as moderately-strong.

Substitute products. In the context of the definition of the public sector geospatial information industry, substitution is not so much a matter of value-for- money on an interindustry basis, but is vested in low vs high price industry groupings. Most government contracts are established in terms of public sector procurement regulations, whereby procurement is largely based on the lowest price offering. It is thus found that public sector organisations are forced to use a private sector contractor with the lowest price, with often a lesser emphasis on meeting specifications. The force of substitution is considered to be weak.

Power of suppliers. Suppliers are deemed to be all public sector organisations with a particular interest in acquiring geospatial information. This is conducted within the ambit of the National Imagery and Mapping Advisory Council (NIMAC) and aims at coordinating, rather than duplicating the acquisition of processed geospatial imagery. For various reasons (mainly high staff turnover and consequently little/no continuation of agreements) however, it would appear that the NIMAC process may not be achieving its full mandate. This force must be regarded as weak.

Power of buyers. Four distinct buyer groups may be identified, DLA, public sector in general, commercial clients and the less informed "illiterate" public. The latter group exerts no power whilst, although competition is fiercest amongst the commercial clients sector, priority needs to be given to the public sector in general, and particularly the DLA who provides a large percentage of the budgetary requirements. In this sense the power of buyers in high.

From the foregoing it may be concluded that the forces at play in the public sector geospatial information industry are mainly weak to moderate, thus collectively making the industry relatively attractive. Furthermore, the fragmented industry structure, consisting of complex networks, presents an opportunity for establishing collaborative partnerships and pooling of financial resources to provide products in the shortest turnaround times (to fend against private sector competition) and by addressing issues of incapacity and budget constraints (to increase overall industry effectiveness).

Industry components that determine an organisation's current position and future competitive success

Industry components relating to the current position and future success of an organisation consist of an industry strategic group map and the industry key success factors. Those two components which may be generated from the industry attractiveness analysis above will be used at a later stage to determine the relative competitive strength of organisations operating in the particular industry.

\section{Industry strategic group map}

A strategic group map displays the different competitive positions that rival organisations occupy in the industry. For the purposes of this research product quality (including currency of information) and the extent of geographic coverage were selected as key criteria to form the variables to construct the map as shown in Figure 1 below. These criteria are considered to be the key aspects for meeting user requirements across government. 


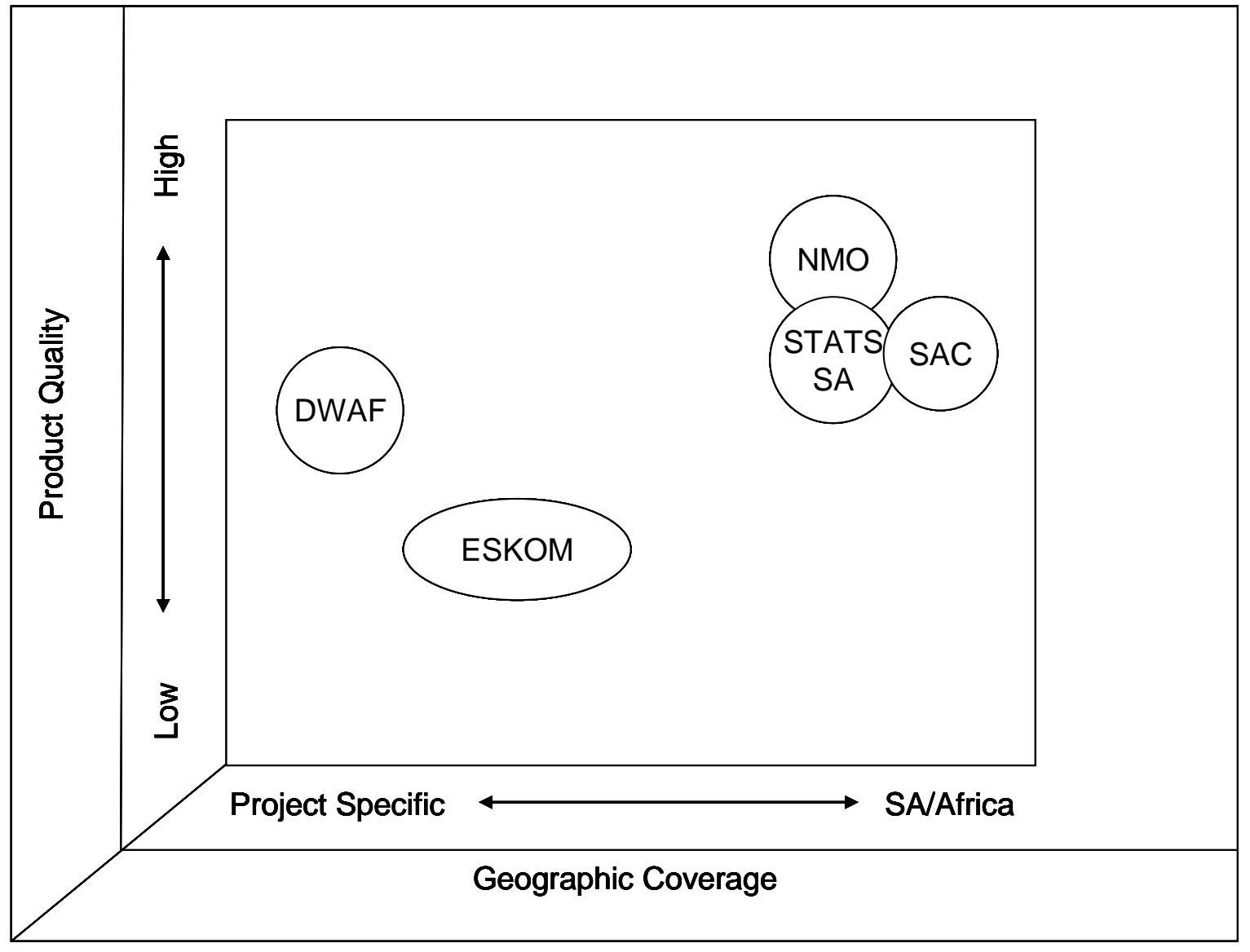

Figure 1: Strategic group map of public sector geospatial information industry

As can be seen, the SAC offers the greatest extent in geographic coverage for geospatial information, with its footprint coverage extending into Africa. For the NMO and Stats SA, coverage lies within the borders of South Africa. Product quality is generally high with the NMO leading the pack. Both Eskom and the Department of Water Affairs and Forestry (DWAF) are very project specific.

\section{Industry key success factors}

Industry key success factors are those competitive factors that most affect industry members' future ability to survive and prosper in that particular industry.

In the public sector geospatial information industry the undoubted overall success factor is the ability to satisfy the government needs for an accurate geospatial dataset covering the entire country. However, a number of other factors also determine an organisation's ability to be judged as distinctly better than rivals. In this regard the following factors are important for the industry under consideration:

- Short turnaround time on the production of the processed earth imagery.

- $\quad$ Coordination between geospatial organisations within the public sector and between the public and private sector industries.
- An image perception that is current and up to date for all public sector users of geographic information.

- $\quad$ The ability to disseminate products over the Internet.

- $\quad$ The ability to attract and retain suitably skilled staff.

Summary: Strategic analysis of the geospatial information industry

From a macro-environmental perspective the key theme that emerges is the political intent to sustain economic and social growth and that the geospatial information industry has a major task to fulfil in this regard. A profile description of the current characteristics of the industry and expected changes reflects a large industry which is expanding at a rapid rate. As such it is attracting increasing numbers of competitors but, as an industry, appears to be slow to adjust to technological advancement. Nevertheless, it is an attractive industry with its structure offering benefits to those industry players who are prepared to collaborate. Within the industry the NMO is relatively well positioned and should lead those industry key success factors which are imperative for its future prosperity. Against this tableau the next section describes the internal environment of the major player in the industry, the NMO. 


\section{Internal strategic analysis of the NMO}

An internal strategic analysis of an organisation typically includes the following: strategic intent, current strategy and value chain (structure and processes). From these latter two analyses strategic business actions and themes may be identified by constructing a strengths, weaknesses, opportunities and threats (SWOT) model and by determining the competitive strength of the organisation. The above-mentioned topics will subsequently be discussed as they relate to the NMO.

\section{Strategic intent}

The strategic intent of an organisation in the private sector is usually embodied in its vision, mission and values. This strategic base is then supported by the operational intent which includes goals, objectives and targets. In the case of an organisation in the public sector, its vision is superseded by the mandates received.

Mandates provide the framework within which the organisation must operate and include both formal (legal statutes) and informal (political) mandates.

Informally the NMO is directed by the main political goal of the DLA, i.e. "to better serve the political requirements for land reform in South Africa” (Denner, 2007:47). This main goal is supported by clear strategic objectives like land rights, provision of access to land, systems and processes, intra-departmental excellence and integrated spatial planning and information. Strategic objectives in turn underpin the specific target of the DLA which is the "redistribution of 30 percent of white-owned agricultural land by 2014" (DLA Strategic Plan, 2005:8).

From a formal perspective the NMO is guided by a number of legal statutes such as the Professional and Technical Surveyors Act (No. 40 of 1984), Land Survey Act (No. 8 of 1997), South Africa Geographical Names Council Act (No. 11 of 1998) and the Spatial Data Infrastructure Act (No. 11 of 1998).

A key concern to the NMO is the fact that the DLA mandates are mainly based on a political agenda of land reform, as prescribed by central government, whilst the vision, mission and values of the NMO are apolitical in nature and focus on creating public value through its activities in order to enhance economic and social growth. This vision, mission and values are next outlined.

The vision of the NMO states: "The Chief Directorate: Surveys and Mapping aspires to be South Africa's foremost supplier of geospatial information and services" (Consultus, 2001:5). It illustrates the apolitical nature of the organisation and is supported by the Mission which clearly embodies the current activities of the NMO in its striving for its future oriented vision: "The organisation strives for excellence through ensuring the availability of reliable up-to-date national survey, mapping and other geospatial information and services, to the public and private sectors, national and international communities and itself" (Consultus, 2001:5).
The strategic pursuit of an organisation's vision and mission is guided by a statement of values which describes the organisation's "way of doing things". The Value Statement of the NMO is as follows: "We are committed to an organisation in which people are proud, self-disciplined, motivated and loyal; in which we can learn, develop and advance through responsible actions and objective decisions. Through excellence in our service and quality in our products will remain flexible to our environment and service oriented to all our clients. By maintaining mutual respect and trust, we retain open and clear communications so as to remain fair and honest in our actions and decisions" (Denner, 2007:51).

Once the organisation has clarity on its strategic intent it follows that it has to decide what strategic actions and approaches it must take to move the organisation along to achieving the intent it has charted, ie. it must decide on its strategy. The current strategy of the NMO is discussed next.

\section{Current strategy}

Porter's generic strategies (Porter, 1980:35) provide for two basic competitive approaches, namely cost leadership and differentiation. Focus or broad, as the third generic approach, is a subset of the other two. The broad cost leadership approach was adhered to by the NMO in the past and was due to the political, social and economic changes; the need for cost effective economic growth as well as the legislative requirement of reduction of costs to buyers demanded by the Promotion of Access to Information Act (No. 2 of 2000) and embodied in the Cost of Fulfilment of User Requirement (COFUR) directive. However, recent efforts amongst public sector organisations to secure multiuser licences for competing products such as satellite imagery, whereby access to these products is free of charge for the public sector users, have caused the strategic emphasis to shift to a focused differentiation strategy, growing market share in the high resolution imagery focus segment by emphasising the quality and features of its products as well as its service. This has lead to the NMO placing a relatively greater emphasis on their, particularly non-price aspects, strategic marketing activities (Denner, 2007:53-61). However, it would appear that still not enough importance is afforded to the customer and his/her needs (Denner, 2007:179). Current strategy is reflected in an organisation's value chain. The next section explores the NMO's value chain, its structure and processes.

\section{Value chain: structure and processes}

All of the various activities that an organisation performs combine to form the value chain which ultimately attracts the target buyers and, in the private sector, translates into profits for the organisation. The concept of a value chain applies similarly to the public sector but the ultimate aim is not profit but to instil trust of stakeholders and confidence in public institutions (Heintzman \& Marson, 2005:549). This aim is underpinned by the sub-aims of client satisfaction and employee engagement. Figure 2 shows Porter's (Porter, 1985:45-48) value chain adapted for a public sector organisation. A brief description as it pertains to the NMO follows. 


\section{Primary activities}

\section{Inbound logistics}

Inbound logistics entails the transportation of raw materials to the point of operation. Aerial photography flown according to the standards and specifications of the NMO is acquired during specific periods, referred to as "windows of opportunity" whereby the specific angle of the sun is conducive to aerial photography. The raw materials also include ancillary data received from outside organisations that may be included in the map information. Examples are the Eskom power line geospatial dataset and geographic names. The responsibility for the delivery of the photography to the NMO premises resides with the contractor appointed to undertake the aerial photography.

\section{Operations}

For the NMO its operations represent those value-adding processes to convert the raw imagery into an orthorectified image and the production of hard copy maps. Operational inefficiencies are caused by staff shortages and a significant lack of research and development into more efficient production methods. As a result, the productive capacity of the organisation is supported extensively by the outsourcing of 75 percent of production. Opportunities for value adding and improving efficiencies on turnaround times of core products exist through the backward vertical integration of the process of imagery acquisition.

\section{Outbound logistics}

In recent years, much of the in-house processing of the NMO has been contracted out to the private sector. These products are then delivered from the contractors to a single point of entry to the NMO, where the receipt of the data is recorded and then disseminated for quality controlling to the various divisions. Contractors are notified of the acceptance or rejection of the contract work via the same point of entry. Value is created in that the contractors are able to produce the required products in shorter turnaround times.

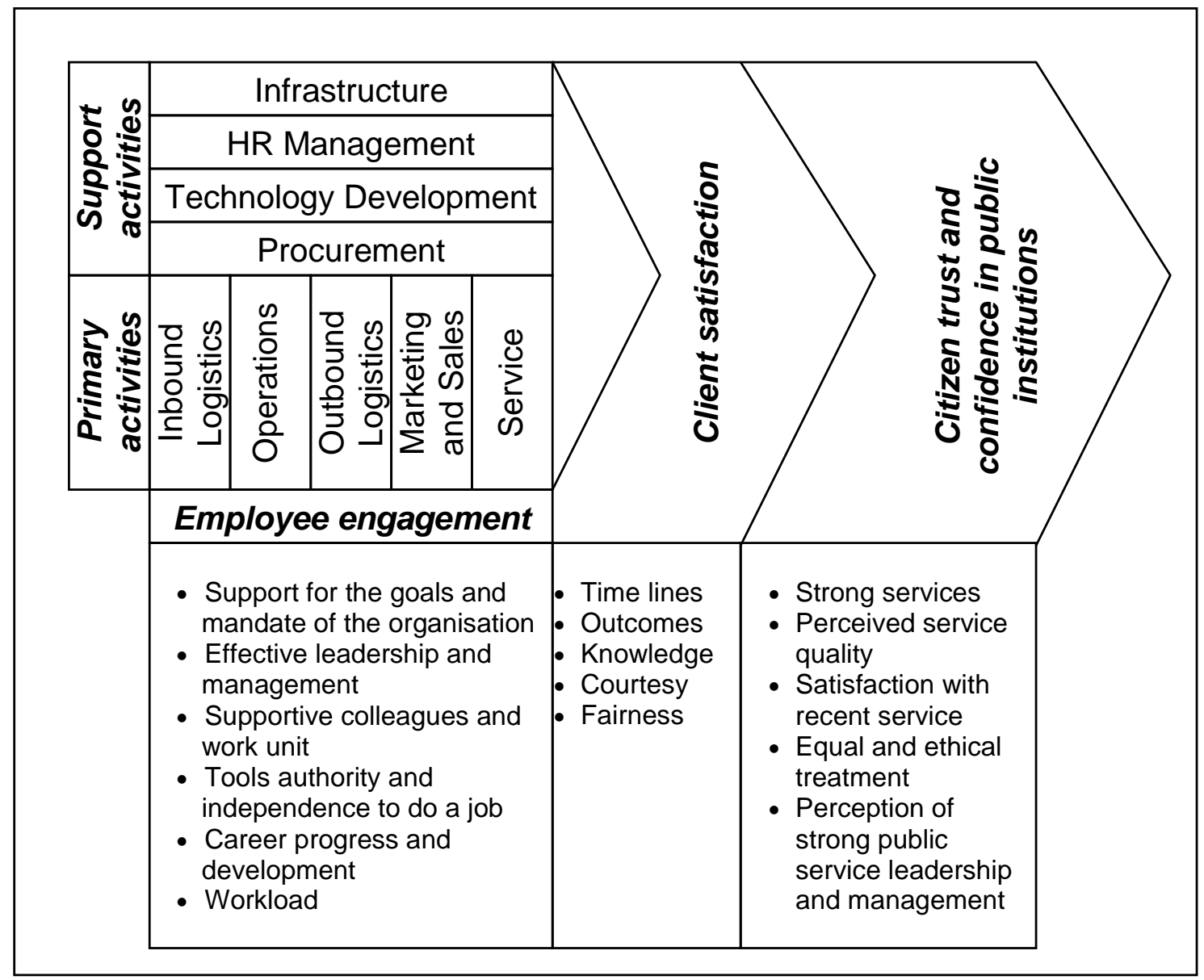

Figure 2: Porter's value chain adopted for a public sector organisation 


\section{Marketing and sales}

The marketing of the products of the NMO is handled internally through the Customer Relationship Marketing (CRM) unit, whilst products are distributed via the Sales division of the organisation. The NMO currently also utilises an extensive network of vendors for distribution of products, with established agreements between the NMO and the respective vendors for the dissemination of products. Further efforts to enhance the distribution of the products include the establishment of an office in Pretoria to provide sales support in the Gauteng region, where many of the users are based. However, with the limited bandwidth available, this office serves merely as a post office for taking of orders for digital imagery, which are then supplied to the clients from the head office in Mowbray. Hard copy copies may be purchased directly from the satellite office in Pretoria.

\section{Service}

With respect to service, it is only the activity of dealing with complaints that applies to the NMO. Complaints are dealt with within the CRM and sales environment, with direct access also available to the head of the organisation in extreme cases.

\section{Support activities}

\section{Infrastructure}

The NMO's business model is based on the concept of grouping related activities in a single division. For instance, the field survey division is responsible for the capturing of all field survey data required by the organisation. The divisions with related activities are grouped under a subdirectorate, accordingly, related sub-directorates are grouped under a directorate. For example, all divisions involved in the cartographic production stages are grouped under the Cartographic Directorate. Each division is managed by a division manager, each sub-directorate by a deputy director and the directors form the heads of each of the three directorates.

\section{Human resource management}

Human resource management is a support activity in the value chain that crosses all the primary activities within the NMO. This function is undertaken with the assistance of the provincial administrative unit, named the Shared Service Centre. Recruitment and selection are undertaken by panels comprising of senior employees of the NMO, with the directors responsible for decisions to be taken. All recruitment and selection are conducted in terms of fulfilling the requirements of the employment equity targets. In the event of there not being suitable candidates from the targeted pool, the position is re-advertised with relaxed conditions. Upon appointment, new personnel are assigned to divisions where the vacancy for which they were appointed, exists. The value that the human resource management creates for stakeholders is often seen as very little in that, whilst compliance to the various policies are ensured, the organisation's failure to retain staff negates the efforts of recruitment and selection.

\section{Technology development}

The NMO is significantly lacking with respect to technology development, mainly due to the limited skills that the organisation is able to retain. Many staff are simply trying to keep abreast with the daily workload, with little time available for any research and development. The NMO has also diversified from its core products to assist the parent department in land reform activities, where many of the NMO staff involved in these activities could perform the much needed research and development required.

\section{Procurement}

Procurement and supply chain management processes are administered externally via a DLA administrative unit, established within each province. As this is an external process to the NMO, the organisation as such has little control over any delays experienced. Such delays impact negatively on turnaround times of products, as contractors refuse to commence any contracts without receipt of an official order. Settling of invoices presents much the same problems and contractors are often reliant on payments for work done before continuing with additional contracts. In terms of improving value for stakeholders the supply chain management and procurement processes seem to remove any gains created from improved turnaround times in the actual primary activities.

Summary and identification of competence, core competence and distinctive competence

Whilst value is created in the various in-house value chain activities, the external (mainly outsourced), deconstructed operations, outbound logistics and procurement processes are not allowing the organisation to realise any benefits from efficiencies it may introduce. Key to achieving efficiencies lies in the human capital, which by all accounts, it is failing to retain.

An analysis of the value chain of an organisation enables the deduction of its competences, core competences and distinctive competences. Thompson, et al. (2007:100-102) describes a competence as an activity that the organisation perform well, whilst a core competence is a relatively important activity that an organisation performs better than other internal activities. A distinctive competence is further described as a competitively valuable activity that the organisation performs better than its rivals. Grouped together, Bryson (2004:41) describes these as the organisation's strongest abilities, most effective strategies and actions, or best resources on which it can routinely draw to enable good performance. A consideration of these competences as it applies to the NMO follows.

In the case of the NMO its competence is regarded as its ability to provide a national coverage of basic geospatial information and maintaining this fundamental dataset. For the NMO a core competence is represented by having the skills to manufacture high quality products at a minimal cost 
to the user. In particular, a core competence further refers to the combination of skills or intellectual capital across the organisation, enabling the NMO to consistently produce a geospatial dataset of very high quality. Finally, the quality and geometric accuracy of its products, unrivalled by its major competitors, must be seen as the NMO's distinctive competence.

\section{Strategic business actions and thrusts}

Strategic business actions and thrusts as it applies to the NMO may be identified by constructing a SWOT model and by determining the competitive strength of the organisation.
The development of both of these tools draws from a previous strategic analysis of the attractiveness of the geospatial information industry and the pre-going discussion of the internal environment of the NMO.

Strengths, weaknesses, opportunities and threats (SWOT)

A comprehensive SWOT analysis appears in Denner (2007:126-148) and, for the purposes of this paper, is summarised in Table 2 below, including the translation of the "four SWOT lists" into strategic actions: SO, ST, WO and WT.

\section{Table 2: A SWOT matrix for the NMO}

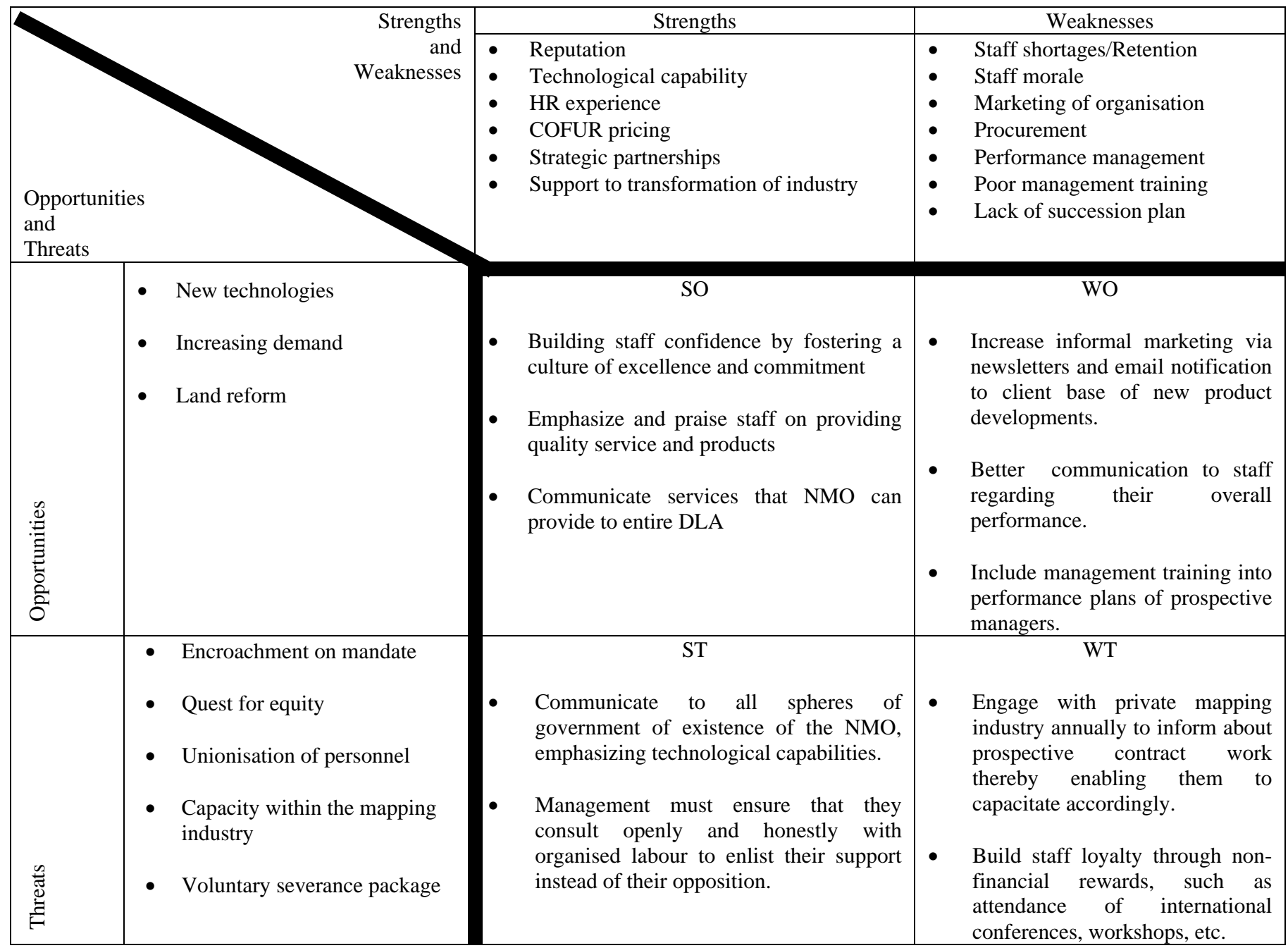

Consideration of the strategic actions identified in Table 2 results in the grouping of these into four relatively homogeneous sets of activities which may form the cornerstones of future strategic thrusts by the NMO:

Staff related: Culture, praise, loyalty.

Communication to: DLA, internal, government, private mapping industry.

Marketing via: Informal media vehicles.
Management: Training and consultation with organised labour.

\section{Competitive strength}

A competitive strength assessment ranks an organisation relative to its major competitors on those factors that are considered to determine success in the industry. A weighted competitive strength assessment of public sector competitors in the geospatial information industry is reflected in Table 3. 
Table 3: Weighted competitive strength assessment of public sector competitors

\begin{tabular}{|c|c|c|c|c|}
\hline Key success factor & Weight & NMO & SAC & $\begin{array}{l}\text { Stats } \\
\text { SA }\end{array}$ \\
\hline Product quality & 0,15 & $8 / 1,20$ & $7 / 1,05$ & $7 / 1,05$ \\
\hline Reputation & 0,05 & $7 / 0,35$ & $7 / 0,35$ & $6 / 0,30$ \\
\hline $\begin{array}{l}\text { Production capability } \\
\text { including } \\
\text { outsourcing }\end{array}$ & 0,10 & $8 / 0,80$ & $8 / 0,80$ & $6 / 0,60$ \\
\hline Technological skills & 0,05 & $6 / 0,30$ & $7 / 0,35$ & $6 / 0,30$ \\
\hline Coverage of product & 0,25 & $6 / 1,50$ & $8 / 2,00$ & $5 / 0,25$ \\
\hline Distribution & 0,05 & $6 / 0,30$ & $7 / 0,35$ & $5 / 0,25$ \\
\hline $\begin{array}{ll}\text { New } & \text { product } \\
\text { innovation } & \\
\end{array}$ & 0,05 & $4 / 0,20$ & $7 / 0,35$ & $5 / 0,25$ \\
\hline Financial resources & 0,10 & $7 / 0,70$ & $5 / 0,50$ & $9 / 0,90$ \\
\hline Relative cost position & 0,05 & $9 / 0,45$ & $8 / 0,40$ & $9 / 0,45$ \\
\hline Customer service & 0,15 & $6 / 0,90$ & $8 / 1,20$ & $6 / 0,90$ \\
\hline $\begin{array}{l}\text { Weighted overall } \\
\text { strength rating }\end{array}$ & 1,00 & 6,70 & 7,35 & 5,25 \\
\hline
\end{tabular}

The most important part of the competitive strength analysis lies in drawing conclusions and translating these into strategic actions and/or thrusts. From this perspective the NMO should protect its relative cost position, as well as enhance its advantage in production capability and maintain its product quality. Plans should be put in place to substantially improve its position in new product innovation.

\section{Summary of SWOT and competitive strength analyses}

Based on the SWOT and competitive strength analyses it would appear that the NMO should build its future business strategic thrusts around the following major themes: staff, communication, marketing, management, production (cost and capability) and product (quality and innovation).

\section{Summary: Internal strategic analysis of the NMO}

The NMO is a well-established public sector entity which functions within political as well as legal mandates. The latter emphasises economic and social growth whilst the former aims at land reform. This divide causes some tension within the organisation. Nevertheless, its vision, mission and values are clearly formulated around a business-related strategic intent and are apolitical in nature. A strategy to achieve the strategic intent has shifted from cost leadership to differentiation with a focus on the high resolution imagery industry segment. This approach requires some emphasis on particularly the non-price elements of the marketing mix. The strategy is well implemented via the value chain activities resulting in a distinctive competence being identified as 'quality and geometric accuracy of products'. Future strategic thrusts have been identified to satisfy the desired value chain outcomes of trust and confidence, client satisfaction and employee engagement. In the next section the positioning of the NMO within the context of its external and internal environments will be explored.

\section{Repositioning the NMO}

\section{Introduction}

The South African public sector geospatial information industry is large and in the rapid growth phase of the industry life cycle. However, it is also very fragmented with respect to the major competitive forces and their constituent parts. As such it displays a complex network-system of inter and intra-industry relationships. Managing these networks has become a major focal point of strategic management in the public sector (Goldsmith \& Eggers, 2004). The NMO is a significant player in the local industry system and it would thus be to its advantage to establish a most favourable position for itself. It operates within specified mandates as well as it own strategic intent. It has a well-formulated strategy with a supportive, albeit somewhat deconstructed, value chain and clearly defined future strategic thrusts developed around a specified distinctive competence. The major issue which the NMO presently faces is how to best reposition itself, given the prevailing and expected conditions in its external environment and its own internal position, currently and as envisaged with regard to future sustainability.

To address this issue this paper now draws on the previous descriptions of the external conditions displayed by the geospatial information industry and the description of the internal position of the NMO. These analyses are merged and explore the viability of repositioning the NMO within the premise of a generic related corporate strategy for those public organisations engaged in the geospatial information industry. The proposed strategy must be generic in order to be applicable to the whole group of role players in the industry and must preferably be related in order to capture competitively valuable cross-business relationships which exist in the respective value chains. Furthermore, such a strategic approach is corporate in nature because it is viewed from the perspective of the "holding company", the government. In particular it will also satisfy one of the key challenges identified by government, namely "a dynamic integrated system where synergistic services are clustered together” (Denner, 2007:181).

The viability of any corporate move must be judged to pass three tests (Porter, 1987:46-49):

- $\quad$ The industry attractiveness test

- $\quad$ The cost of entry test

- $\quad$ The better-off test.

\section{The industry attractiveness test}

The geospatial information industry is large, is in its rapid growth phase and is considered attractive when based on a competitiveness analysis. 


\section{The cost of entry test}

This test implies that the cost to enter into a particular formal relationship must not be so high as to erode the potential for good profitability. Adapted to the public sector the cost of creating a (set of) relationship must not be so high as to erode the potential for increased stakeholder value. Essentially this would mean a reorganising of departments, or removing certain activities from departments and grouping them to form a more efficient and effective service delivery. Restructuring could occur, but this is in line with one of the central themes of government, which is to look at how much more stakeholder value could be achieved through better reorganisation of government. Government expenditure would ultimately be decreased as more organisations become aware of a geospatial portal and cease to engage in duplicate efforts through lack of knowledge of the activities of other government departments.

\section{The better-off test}

The better-off test implies that the envisaged new set of interorganisational entities will perform better together than they would as independent stand-alone organisations. This can be achieved if sufficient related strategic fits exist between the organisational value chains. Figure 3 below provides an insight into the many potential synergies that exist between the value chain activities of the three major players in the public sector industry.

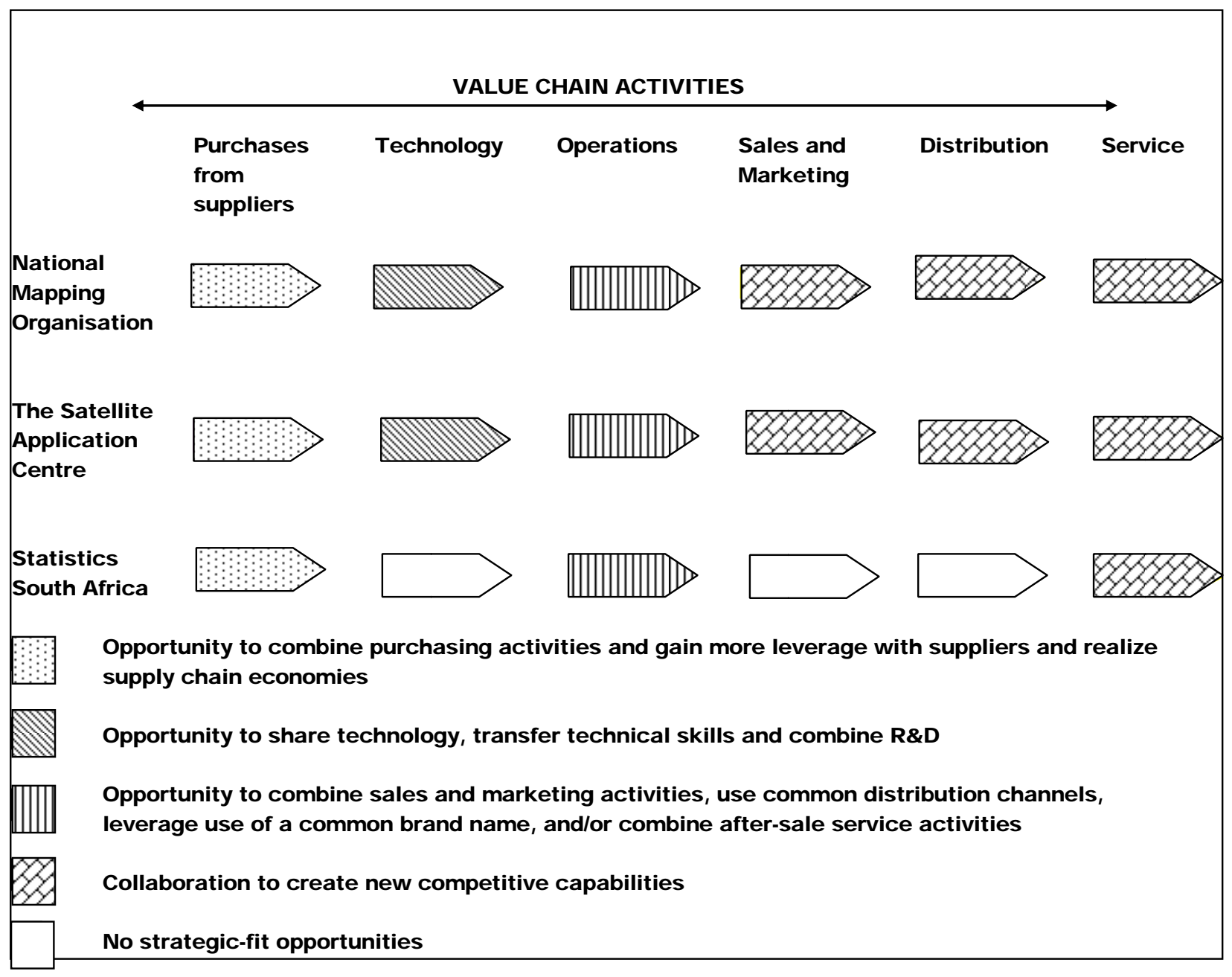

Figure 3: Strategic value chain synergies between the NMO, SAC and Stats SA. 


\section{Conclusion}

In conclusion, the proposed grouping of the geospatial activities under a single umbrella within government with diversified business units has been found to pass all three tests.

\section{Summary, conclusions and recommendations}

This paper described the structure and environment of South African government departments which are related to geospatial information and in particular the evolving positioning of the NMO. In this regard a paucity of current information was found to exist, compared to developments in the public sector geospatial information industries in other countries. An analysis of the local situation in this industry revealed a large and growing, but fragmented and complex system of inter and intra-industry networks. It is not considered to be most favourably coordinated in its present configuration. The NMO is a prominent member of the industry and strategically sound. However, it has been shown that the NMO can successfully be repositioned in a generic related corporate system which will contribute to the advantage of the entire industry.

It may be concluded that, as geospatial information is seen as providing a basis to foster sound economic and social growth for a developing country, it is crucial that this remains a key function of central government. However, this paper has found that the NMO in South Africa is inappropriately positioned within government. To create a more streamlined and effective public sector service delivery of geospatial information, would require a reorganisation of those business units with related value chain activities under a unified corporate umbrella to provide a single portal that is widely accepted as the foremost supplier of geospatial information. The paper has presented an example of how delivering an efficient and effective service delivery is hampered through the inappropriate organisation of public sector activities in South Africa, ultimately impeding progress towards achieving the strategic objectives of the Accelerated Shared Growth Initiative for South Africa (AsgiSA). The government is therefore left little alternative but to revisit the strategic positioning of public sector organisations engaged in the provision of geospatial information if it is committed to fostering sound and sustainable economic and social growth.

It is recommended that a more detailed analysis of the economic and social contribution made by geospatial activities in South Africa is undertaken. This would provide the public sector with greater knowledge of the extent and capacity of the industry to cope with the full extent of the geospatial work currently being contracted out by government and for future decision making processes. A more detailed analysis of the economic and social contribution of geospatial activities in South Africa would also provide key role players with an understanding of the strategic importance of such information and lead to value being placed on the availability of such a key resource.
Finally, for the NMO, a detailed product analysis, coupled with an extensive user needs analysis conducted by experienced marketing professionals will provide evidence of the need for the organisation to customise its products to better suit the business needs of its clients. This analysis should be completed on a regular basis to understand the changing factors influencing the industry and to guide them in shaping their future survival strategies. Because the country is in such a significant growth phase, it is necessary that these analyses be conducted every two to three years to ensure relevance of information. It is important to ensure the future survival of the organisation. This can only be done through effective leadership that shares in the vision of the supply of geospatial information to foster economic and social growth opportunities. Much needs to be done to determine a thorough understanding of the existing skills within the organisation. A thorough skills audit that identifies key skills and leadership qualities that can be nurtured and developed through proper management training programmes must be completed as a matter of urgency.

\section{References}

Bryson, J.M. 2004. Strategic planning for public and nonprofit organisations - A guide to strengthening and sustaining organisational achievement. $3^{\text {rd }}$ Edition SanFrancisco: Jossey-Bass.

Consultus, 2001. Report on the strategic planning workshop for the Chief Directorate: Surveys and Mapping. November. Bellville: USB.

Denner, M. 2007. 'Reorganising public sector activities: A case study of national mapping activities in South Africa'. Research Report presented in partial fulfilment of the requirements for the degree of Master of Business Administration at the University of Stellenbosch Business School.

DLA. Department of Land Affairs, Republic of South Africa. 2005: Strategic Plan, 2005-2010. Pretoria:

Economic Commission for Africa. 2003. Public sector management reforms in Africa: Lessons learned. Addis Ababa: Development Policy Management Division.

Fraser-Moleketi. G. 2007. Speech to the South African Local Government Association (SALGA) National Conference, 24 April.

Goldsmith, S. \& Eggers, W.D. 2004. Governing by networks - The new shape of the public sector. Washington, D.C.: Brookings Instution Press.

Heintzman, R. \& Marson, B. 2005. 'People, service and trust - Is there a public sector value chain?' International Review of Administrative Studies, 7(4):549-575.

Lenepa, G. 2006. 'The machinery of the South African government in a nutshell', Professional Management Review, 17(08):24. 
Maquire, D. 2003. 'The impact of global change and the future of national mapping agencies'. Paper delivered at the Cambridge Conference of National Mapping Organisations Cambridge, July.

Porter, M. 1980. Competitive strategy. New York: The Free Press.

Porter, M. 1985. Competitive advantage. New York: Thre Free Press.

Porter, M. 1987. 'From competitive advantage to corporate strategy’, Harvard Business Review, May-June:43-59.

Thompson, A.A., Strickland, A.J. \& Gamble, J.E. 2007. Crafting and executing strategy. Boston, Burr Ridge: McGraw-Hill Irwin. 